\title{
Análise do conhecimento das puérperas em situação de emergência com os bebês
}

\author{
Knowledge analysis of puerperal in emergency situations as babies \\ Análisis de conocimientos de las puérperas en situaciones de emergencia con bebés
}

Recebido: 15/09/2021 | Revisado: 22/09/2021 | Aceito: 26/09/2021 | Publicado: 27/09/2021

\author{
Marcos José Vilchez David \\ ORCID: https://orcid.org/0000-0002-8794-1473 \\ Universidade Veiga de Almeida, Brasil \\ E-mail: marcosjvdavid@gmail.com \\ Vladimir Chaves Fernandes \\ ORCID: https://orcid.org/0000-0002-1184-8109 \\ Universidade Veiga de Almeida, Brasil \\ E-mail: vladimircf@globo.com \\ Abilene do Nascimento Gouvêa \\ ORCID: https://orcid.org/0000-0002-3033-5069 \\ Universidade Veiga de Almeida, Brasil \\ E-mail: abilenegouvea@gmail.com \\ Maria Virginia Godoy da Silva \\ ORCID: https://orcid.org/0000-0003-3980-042X \\ Universidade Veiga de Almeida, Brasil \\ E-mail: godoysilva@terra.com.br \\ Elson Santos de Oliveira \\ ORCID: https://orcid.org/0000-0001-9377-0140 \\ Universidade Veiga de Almeida, Brasil \\ E-mail: elsonbaleiro@hotmail.com \\ Luiza Vilchez David \\ ORCID: https://orcid.org/ 0000-0002-1493-394X \\ Universidade Veiga de Almeida, Brasil \\ E-mail: luizavildavid@hotmail.com \\ Juliana Lana Querino de Oliveira \\ ORCID: https://orcid.org/0000-0002-0472-7480 \\ Universidade Veiga de Almeida, Brasil \\ E-mail: juquerino3@gmail.com
}

\begin{abstract}
Resumo
Objetivo: Analisar o conhecimento das puérperas em situações de emergência domésticas que envolvam os lactentes. Metodologia: Trata-se de um estudo exploratório com abordagem quantitativa realizado no mês de maio de 2021 em um hospital universitário localizada na cidade do Rio de Janeiro. A coleta de dados foi por meio de questionários anônimos, com perguntas estruturadas, de modo fechado, auto preenchidos pelas puérperas. Resultados: A partir desta pesquisa, contatou-se que $83 \%$ das puérperas entrevistadas não receberam durante as consultas de pré-natal, algum ensinamento sobre primeiros socorros aos lactentes pelo profissional da saúde que a assistia. Além deste ponto destacado, vale ressaltar que $100 \%$ das entrevistadas gostariam de receber informações dos profissionais da saúde de como prestar socorro aos bebês. Conclusão: Se as grávidas e puérperas tivessem, durante as consultas de pré-natal e pós-natal, algum ensinamento ou orientação pelo profissional da saúde sobre como agir em situações de emergência com o bebê, os problemas seriam mais fáceis de diagnosticar, pois as mães saberiam identificar o que o filho apresenta e saberiam prestar um atendimento assertivo para aumentar a sobrevida da vítima. O profissional da saúde que assistiria esta puérpera, deveria dar um enfoque maior em como prestar atendimento em vítimas com obstrução de vias aéreas, queimadura por temperaturas elevadas e crise convulsiva, pois a partir do estudo desta pesquisa, pode-se observar que estas foram as questões que as puérperas possuem maior dúvida.
\end{abstract}

Palavras-chave: Emergência; Lactentes; Primeiros socorros; Puérperas.

\section{Abstract}

Objective: Analyze the knowledge of the puerperal in domestic emergency situations involving infants. Methodology: Exploratory field study with quantitative approach that will be held at in in the month of May 2021 university hospital located in the city of Rio de Janeiro. The data collection was through anonymous questionnaires, with closed structured questions, self-filled by the puerperal. Results: From this research, it was found that $83 \%$ of the mothers interviewed were not received during prenatal consultations, some teaching about first aid to infants by the health professional who assisted them. In addition to this highlighted point, it is noteworthy that $100 \%$ of respondents would like to receive information from health professionals on how to provide assistance to babies. Conclusion: If pregnant and puerperal had, during prenatal and postnatal appointments, some teaching or guidence by the health professional 
on how to act on emergency situations with the baby, the problems would be easier to diagnose, because the mothers would know how to identify what the child has and would know how to provide an assertive care to increase the victim's survival. The interviewees showed interest in receiving information's from health professionals on how to provide aid to babies.

Keywords: Puerperal; Infants; Emergency; First aid.

\section{Resumen}

Objetivo: Analizar el conocimiento de las puérperas en situaciones de emergencia domiciliaria que envuelvan los lactantes. Metodología: Estudio de campo, exploratorio con abordaje cuantitativa y realizado en un hospital universitario en la ciudad del Rio de Janeiro. La coleta de dados fue por medio de cuestionarios anónimos, con cuestiones cerradas, completado por las puérperas. Análisis de los dados: A partir de esta pesquisa, es posible identificar que $83 \%$ de las puérperas entrevistadas no recibieron durante las consultas de prenatal, algún ensinamiento sobre los primeros auxilios a los lactantes por los profesionales de la salud que la acompañaba. Además de esto, se resalta que $100 \%$ de las entrevistadas gustarían recibir informaciones de los profesionales de la salud de cómo prestar auxílio a los bebés. Conclusión: Si las mujeres embarazadas y puérperas tuvieran, durante las consultas de prenatal y postnatal, algún enseñamiento u orientación por algún profesional de salud en cómo hacer en situaciones de emergencia con el bebé, los problemas serían más fáciles de hacer un diagnóstico, porque las madres sabrían identificar que el hijo presenta y prestaría un atendimiento de forma correcta para aumentar la sobrevida de la víctima. Las entrevistadas presentaran interés de recibir informaciones de los profesionales de salud de como prestar un atendimiento a lo bebé.

Palabras clave: Puérperas; Lactantes; Emergencia; Primeros auxilios.

\section{Introdução}

$\mathrm{O}$ interesse pela área de emergência e o desejo de ajudar aos pais e familiares em situações de emergências domésticas, para que saibam agir em casos inesperados salvando a vida de um lactente, motivou essa pesquisa.

No ano de 2019, foram contabilizados 1.271 óbitos em domicílios referentes a faixa etária de 0 a 364 dias. Dos 1.271 óbitos, 651 poderiam ter sido evitados por práticas de primeiros socorros. Entre os 651 casos, 568 óbitos foram referentes a respiração; 44 óbitos por queda; 24 óbitos por afogamento e submersão acidental; 8 falecimentos devido à exposição ao fumo, fogo e às chamas e 7 mortes por exposição a correntes elétricas e temperaturas extremas (DATASUS, 2020).

A atuação da enfermagem no período do pré-natal e pós-natal é de suma importância tanto para a mãe, quanto para o lactente, onde é um momento em que o Enfermeiro irá prestar sua assistência de forma qualificada e baseada em seus conhecimentos científicos.

Em estudo recente, realizado com gestantes, a figura do enfermeiro foi delineada como alguém que passa segurança, ancorando-se na ideia de que pondo em prática aquilo que lhes é orientado, a culminância se dará com o nascimento de um bebê saudável. Mesmo assim, coloca em pauta a necessidade de melhorias na gestão do atendimento devido a questões intrínsecas à equipe de saúde e gestores, como a disponibilidade de tempo e estrutura de qualidade. Este estudo trata da consulta de enfermagem com gestantes e puérperas, uma atividade para enfermeiros (Melo, Silva, Matos, \& Martins, 2020). A enfermagem está buscando cada vez mais a consolidação da autonomia profissional, respeitando os aspectos legais que compõem a profissão (Castro Júnior et al., 2020).

O Conselho Federal de Enfermagem (COFEN) assegura e regulamenta a atuação dos profissionais de enfermagem e destaca que a Consulta de Enfermagem é privativa do profissional Enfermeiro, conforme está disposto na Lei $\mathrm{n}^{\circ} 7.498$, de 25 de junho de 1986 (COFEN, 1986).

Nas consultas de pré-natal, em todos os casos, foram realizados a prática do exame físico obstétrico completo, aferição de peso e pressão arterial, medição da altura uterina, ausculta de batimentos cardíacos fetais quando em idade gestacional adequada ao exame, solicitação de todos os exames cabíveis a cada trimestre gestacional, com os devidos registros na caderneta da gestante (Livramento et al., 2019). 
Em relação as consultas no período pós-natal, a primeira consulta do recém-nascido deverá ocorrer na sua primeira semana de vida, que constitui um momento propício para estimular e auxiliar a família nas dificuldades do aleitamento materno exclusivo, para orientar e realizar imunizações, para verificar a realização da triagem neonatal (teste do pezinho) e para estabelecer ou reforçar a rede de apoio à família (SBP, 2006). Nessa primeira consulta, serão realizados anamnese, exame físico completo, avaliações e orientações (Brasil, 2012).

Muitos profissionais da saúde, utilizam o Caderno de Atenção Básicas, cujo é fornecido pelo Ministério da Saúde, onde o objetivo é de contribuir nas ações desenvolvidas por todos os profissionais de saúde.

Com relação à saúde do bebê, o Caderno de Saúde da Criança fornecido pelo Ministério da Saúde, apresenta um tópico relacionado aos acidentes no público entre 0 e 10 anos. De acordo com esse caderno, os menores de 2 anos estão com os riscos impostos por terceiros, como queimaduras, intoxicações, colisão de automóvel e quedas como forma de conscientização dos responsáveis, aconselham a realizar campanhas de prevenção (Brasil, 2012).

Mais de $90 \%$ das mortes causadas por aspiração de corpo estranho em crianças ocorrem em indivíduos menores de 5 anos, e a maioria desses casos afeta crianças menores de 1 ano (Abder-Rahman, 2009). Vale destacar a faixa etária de zero a seis meses, pois o índice de ocasionar um acidente por engasgo ou queda do trocador durante a troca de fraudas, é maior do que outros tipos de acidentes (Genesini, dos Santos, Conte, Lohmann, \& Zanotelli, 2021).

O treinamento de primeiros socorros não deve ser destinado apenas para profissionais da saúde, mas sim para pessoas leigas de toda a sociedade. Prestar o socorro não se resume apenas a aplicar a técnica aprendida. É importante analisar a cena do local, como a vítima se encontra e chamar ajuda (Ragadali, Pereira, Leal, Anjos, \& Loose, 2015).

Ao capacitar o leigo em situações de emergência e atendimento precoce, irá prevenir sequelas e salvar vidas de outras pessoas. É muito importante que seja ensinado a esses leigos por meio de memorização e sequencias de fácil aprendizado, pois terão uma boa aplicação na prática e, consequentemente, irão atender de forma adequada e com melhora de sobrevida (Pergola \& Araujo, 2008).

A American Heart Association (AHA), a partir do ano de 2010, passou a considerar o atendimento prestado pelo leigo de forma facilitada e de imediato, conforme mostra nas diretrizes da AHA (2010). Segundo a atualização da AHA em 2015, mostra a importância do leigo no atendimento do suporte básico de vida (SBV) e também é apontado que os primeiros socorros podem ser iniciados por qualquer pessoa e em qualquer situação. Capacitar a população sobre o suporte básico de vida, é fundamental, pois caso tenha alguma situação de emergência, as pessoas saberão prestar o atendimento e aumentará as chances de sobrevivência e antecipa o atendimento de emergência prestado pela equipe multiprofissional (AHA, 2015).

O objetivo é analisar o conhecimento das puérperas em situações de emergência domésticas que envolvam os lactentes.

\section{Metodologia}

Trata-se de um estudo de campo, exploratório com abordagem quantitativa realizado no mês de maio de 2021 em hospital universitário localizada na cidade do Rio de Janeiro. A coleta de dados foi por meio de questionários anônimos, com perguntas estruturadas, de modo fechado, auto preenchidos pelas puérperas.

Segundo Knechtel (2014), a pesquisa quantitativa é uma modalidade de pesquisa que atua sobre um problema humano ou social, é baseada no teste de uma teoria e composta por variáveis quantificadas em números, as quais são analisadas de modo estatístico, com o objetivo de determinar se as generalizações previstas na teoria se sustentam ou não.

A pesquisa quantitativa ligada diretamente à quantificação dos dados, experimentação, mensuração e no controle rigoroso dos fatos, esse tipo de pesquisa foi a base do pensamento científico até a metade do século XX e é caracterizado pela passividade e neutralidade do pesquisador diante da investigação da realidade. Nesse tipo de pesquisa, terá uma investigação 
que tem por base a quantificação dos dados e buscará medir opiniões e informações utilizando os recursos da estatística, como a porcentagem, a média e o desvio-padrão (Knechtel, 2014).

A população foi composta por puérperas que estão presentes na sala de espera da primeira consulta de retorno após o nascimento do lactente.

A amostra por conveniência foi composta por aquelas que desejem participar do estudo. A justificativa foi ouvir a opinião dessas puérperas para saber seu acesso à informação com enfermeiros sobre primeiros socorros em lactentes.

O estudo foi iniciado a partir do consentimento devidamente informados e assinado. Não foram utilizados recursos de áudio e imagem e garantida a retirada do consentimento e de participação no estudo a qualquer momento.

A entrevista e a coleta de dados tomaram início após a aprovação do Comitê de Ética em Pesquisa da Universidade Veiga de Almeida (CEP/UVA), de acordo com a Resolução n. ${ }^{\circ}$ 466/12 do Conselho Nacional de Saúde (CNS) com o Certificado de Apresentação para Apreciação Ética (CAAE) - 46150121.5.0000.5291

\section{Resultados e Discussão}

Os dados quantitativos foram compilados e apresentados em tabelas de frequências e analisados para verificação de associações e correlações entre as variáveis apresentadas.

Na primeira etapa, ocorreu a sistematização dos dados quantitativos e posterior análise com auxílio do software estatístico. Foram descritas as frequências de respostas para os principais temas, e também serão realizadas análises multivariadas e correlações das variáveis.

Os sujeitos da pesquisa foram 12 puérperas, na primeira consulta de retorno, após o nascimento do recém-nascido. Foram selecionadas aquelas que manifestaram voluntariamente sua concordância em participar e de acordo com sua disponibilidade. Não houve a necessidade de selecionar ou excluir nenhuma entrevistada. Após o preenchimento do questionário, as puérperas foram orientadas sobre a realização dos primeiros socorros. Esta orientação foi efetuada com auxílio de um bebê manequim, a fim de facilitar a explicação e deixar de uma maneira mais didática. Para realizar a análise dos dados, foram utilizadas técnicas estatísticas através de frequência simples e percentual.

\section{Riscos:}

A participação neste estudo foi voluntária e a mesma não acarretará riscos aos participantes. Desconfortos poderão ser vivenciados durante o preenchimento de um questionário, a partir da lembrança de momentos difíceis ou experiências de desconforto no passado. Nesse caso, o devido acolhimento será prestado ao participante pela equipe do projeto e encaminhados a um serviço de apoio psicológico caso necessário. Não existirão despesas ou compensações pessoais ou financeiras para nenhum participante em qualquer fase do estudo. Não haverá compensação financeira relacionada à participação.

\section{Benefícios:}

A participação no estudo terá benefícios importantes para analisar se as puérperas tiveram acesso à informação durante ou após o pré-natal acerca dos primeiros socorros nos lactentes, identificando se as mesmas obtiveram acesso à informação sobre primeiros socorros em alguma consulta do pré-natal com os Enfermeiros e se as puérperas tiveram este tipo de ensinamento, identificar se as mesmas estão realmente capacitadas para situações de emergência.

Os sujeitos da pesquisa foram puérperas que estavam indo à primeira consulta de retorno, após o nascimento do recém-nascido. Foram selecionados intencionalmente aquelas que manifestaram voluntariamente sua concordância em 
participar e de acordo com sua disponibilidade. Foi entregue, às entrevistadas, o Termo de Consentimento Livre e Esclarecido (TCLE), para que fosse lido e assinado pelas mesmas.

Como todas as entrevistadas aceitaram em fazer parte da pesquisa e nenhuma deles entraram no critério de exclusão, não houve a necessidade de selecionar ou retirar a entrevistada.

O levantamento de dados foi conduzido no próprio local das consultas pelo pesquisador que forneceu orientações sobre o preenchimento da entrevista semiestruturada após a consulta médica de retorno.

As 12 perguntas são estruturadas, de modo fechado, auto preenchidos pelas entrevistadas, a partir de assuntos relacionados ao conhecimento da puérpera em relação de prestar os primeiros socorros aos bebês, sendo elas: obstrução de via aérea parcial e total, queda do bebê, queimadura de pele e crise convulsiva.

Todos os dados foram coletados pelo pesquisador. O tempo médio de duração para o preenchimento dos instrumentos foi de 10 minutos. A pesquisa conteve uma amostra de 12 entrevistadas que foram as puérperas. $\mathrm{O}$ espaço amostral foi reduzido devido à pandemia da SARS-CoV-2, pois a primeira consulta de pós-natal era realizada somente uma vez na semana, em um determinado horário e com um número reduzido de atendimentos.

Após o preenchimento do questionário, foram orientadas, às puérperas, a forma que deveria ser feito os primeiros socorros. Esta orientação foi efetuada com auxílio de um manequim do modelo de um bebê, afim de facilitar a explicação e deixar de uma maneira mais didática. Os tipos de socorros que foram abordados na orientação, foram os mesmos do questionário, preenchido pela puérpera. Após o ensinamento recebido, foi perguntado se a puérpera possuía alguma dúvida e a questão era solucionada no mesmo momento. Esta orientação teve duração de 10 minutos.

Os resultados advindos da entrevista, foram tabulados em planilhas eletrônicas do Microsoft Excel 2016 e analisados os estatisticamente pelo próprio pesquisador. Foram utilizadas técnicas estatísticas através de frequência simples e percentual.

Neste sentido, os resultados foram estruturados em gráficos, de maneira a possibilitar a visualização dos dados e análise das informações. Que serão analisados a seguir: Figura 1 - Gráfico da idade média das puérperas, refere-se ao perfil sóciodemográfico das entrevistadas, onde busca identificar a idade média das puérperas que participaram do questionário e consta uma média de 30 anos de idade.

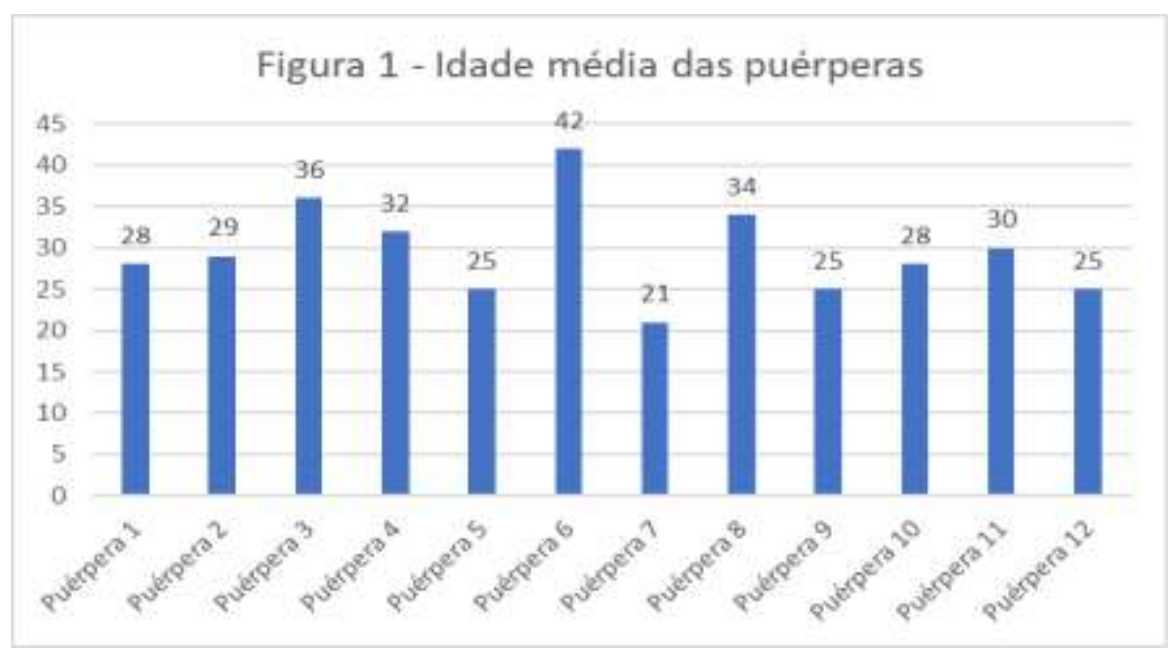

Fonte: Autores (2021).

Na Figura 2 - Gráfico do perfil sociodemográfico das puérperas entrevistadas: escolaridade. Pode-se concluir que $17 \%$ das entrevistadas possuem ensino fundamental, $42 \%$ possuem ensino médio e $42 \%$ possuem ensino superior. 


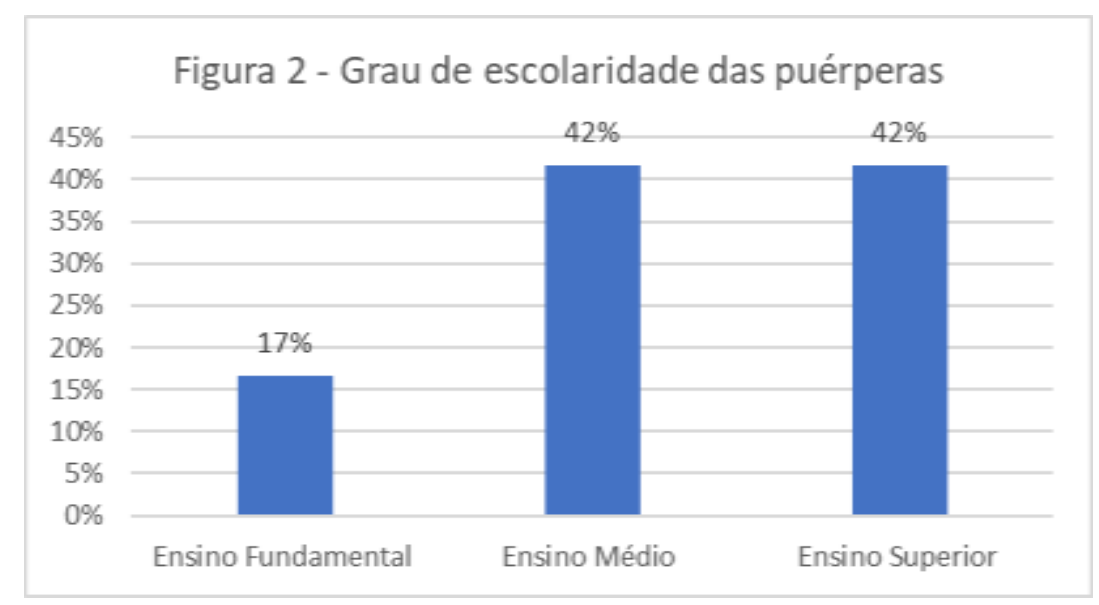

Fonte: Autor, 2021.

Dando continuidade aos resultados, na Figura 3 - Gráfico de porcentagem de resposta das puérperas entrevistadas: Você sabe prestar socorro em situações de emergências, como por exemplo, engasgo e queda em bebês? Demonstra que 33\% das puérperas dizem saber prestar socorro a um bebê, porém $67 \%$ das entrevistadas não sabem prestar socorro aos bebês em situações de emergência.

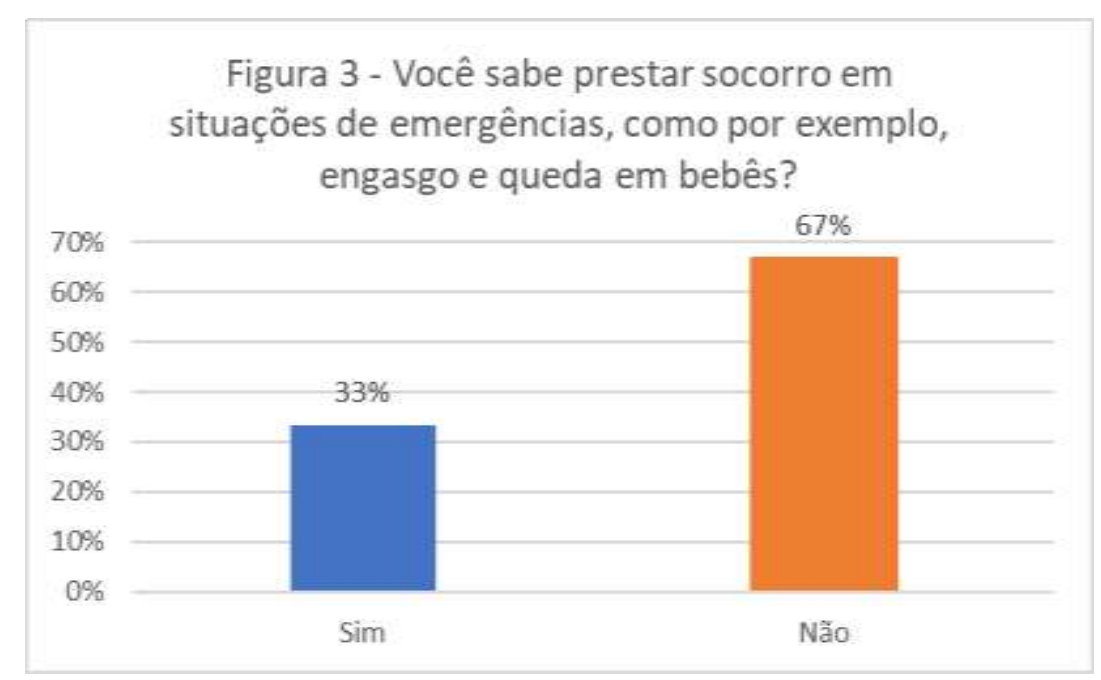

Fonte: Autores (2021).

$\mathrm{Na}$ figura anterior, foi analisado a porcentagem das puérperas que sabiam agir em situação de emergência, e o resultado encontrado onde as puérperas responderam "SIM", que sabiam prestar algum socorro, é de 33\%. Na Figura 4 Gráfico de porcentagem de resposta das puérperas entrevistadas: Você pesquisou em algum site sobre como agir em situações de emergências com o bebê? Dentro deste quantitativo descrito, 75\% disseram ter buscado informação em site de busca, pois presenciou uma situação de emergência com o próprio filho, sendo a principal intercorrência, a obstrução de vias aéreas em bebês e $25 \%$ das puérperas disseram não ter pesquisado em nenhum site de busca. 


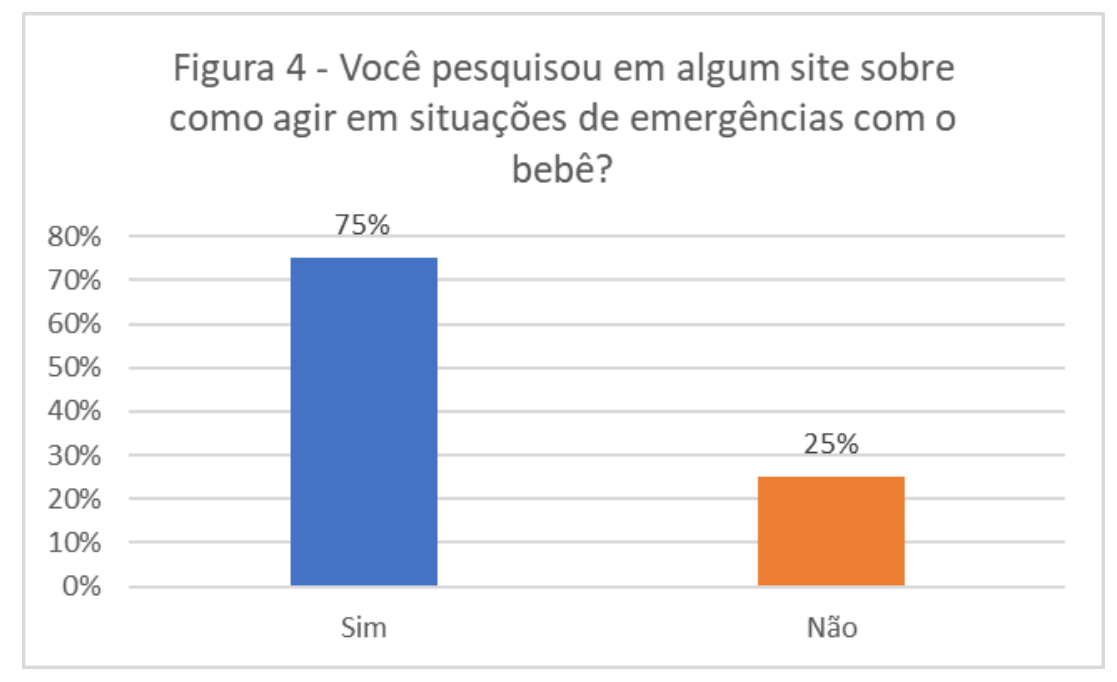

Fonte: Autores (2021).

De acordo com Livramento et al. (2019), as consultas de pré-natal dão um enfoque maior as questões maternas, como por exemplo, os exames que a gestante deve realizar de acordo com a idade gestacional e os profissionais acabam deixando de lado as dúvidas que essas futuras mães terão com o bebê.

Na Figura 5 - Gráfico de porcentagem de resposta das puérperas entrevistadas: Durante as consultas de pré-natal, você teve acesso a como socorrer bebês em situações de emergência? Apresenta uma análise primária das puérperas, para saber se as mesmas tiveram, durante as consultas de pré-natal, acesso às informações sobre primeiros socorros pelo profissional da saúde que a assistia. Do resultado obtido, $17 \%$ das entrevistadas possuíram acesso às informações pelo profissional da saúde e 83\% disseram não ter tido acesso a essas informações através do profissional de saúde.

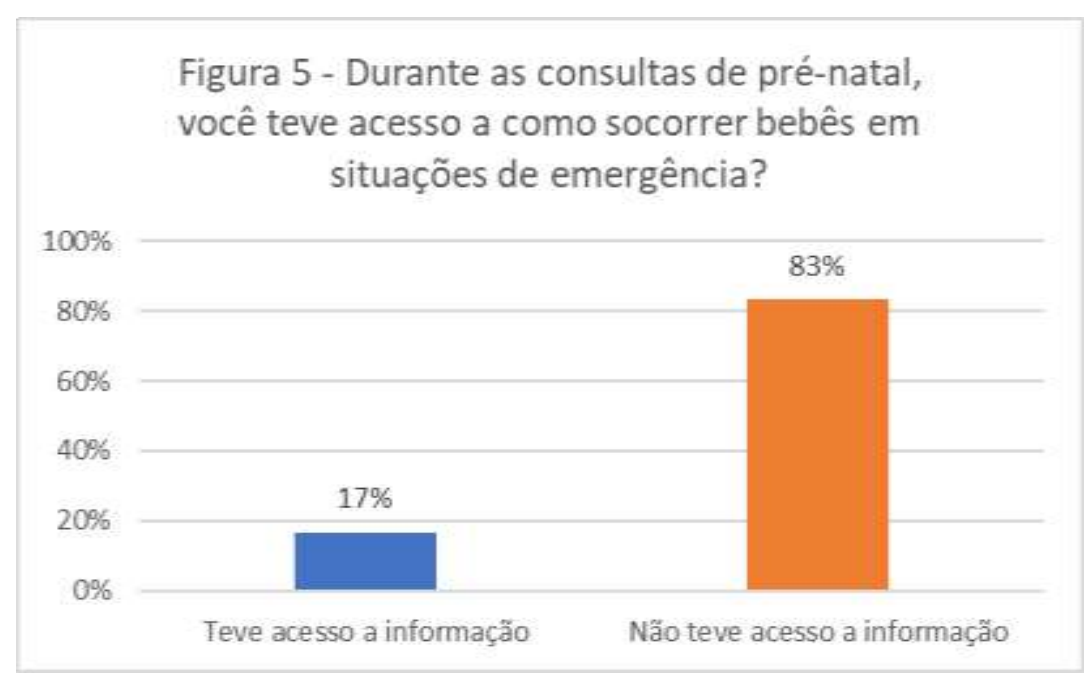

Fonte: Autores (2021).

Conforme a citação de Pérgola e Araújo (2008), ao capacitar o leigo em situações de emergência e atendimento precoce, irá prevenir sequelas e salvar vidas de outras pessoas.

Dando continuidade a leitura do gráfico, pode-se contatar que na Figura 6 - Gráfico de porcentagem de resposta das puérperas entrevistadas: Se não teve acesso a essas informações durante suas consultas no pré-natal, você acha importante aprender os primeiros socorros em bebês? Conforme as respostas, $100 \%$ das entrevistadas gostariam de receber informações dos profissionais da saúde de como prestar socorro aos bebês. 


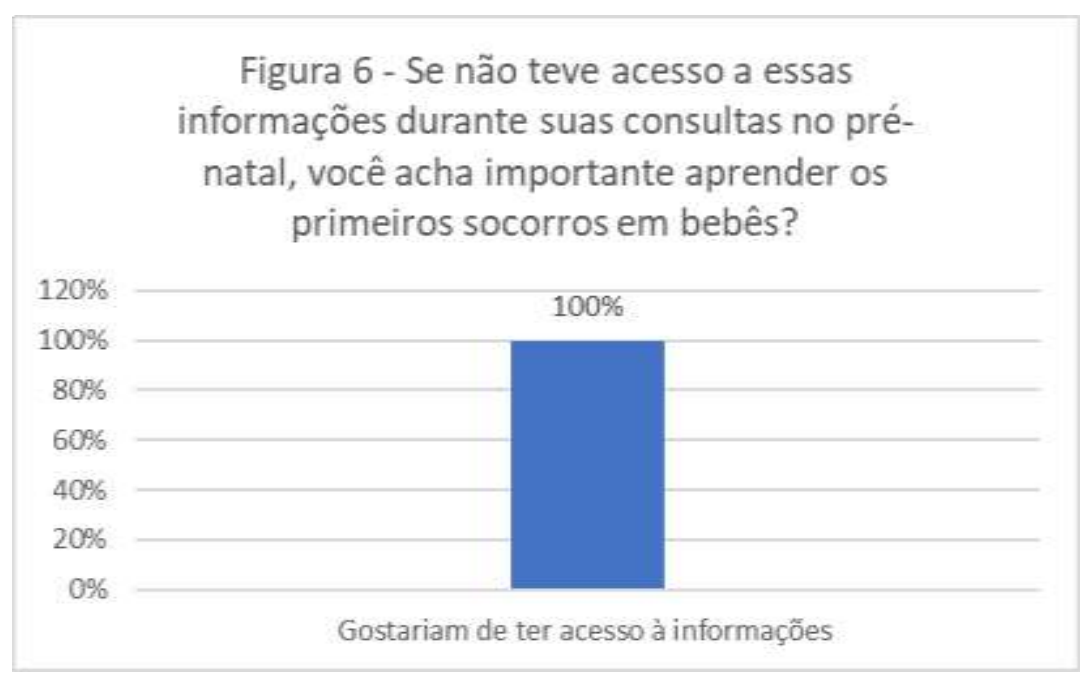

Fonte: Autores (2021).

Na Figura 7 - Gráfico de porcentagem de resposta das puérperas entrevistadas: Você sabe identificar um engasgo parcial? Apresenta o resultado do questionário respondida pelas puérperas e busca identificar se as mesmas sabem identificar um engasgo parcial. Pode-se identificar que $58 \%$ das puérperas sabem identificar, porém $42 \%$ não sabem identificar um engasgo parcial.

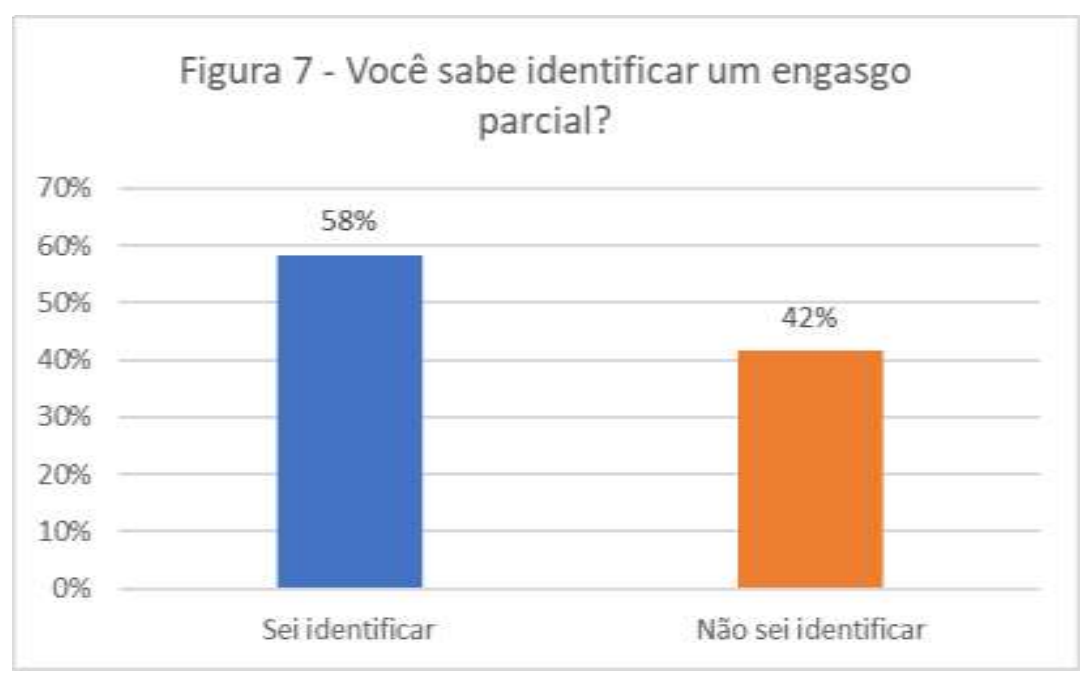

Fonte: Autores (2021).

De acordo com Abder-Rahman (2009), mais de 90\% das mortes causadas por aspiração de corpo estranho em crianças ocorrem em indivíduos menores de 5 anos, e a maioria desses casos afeta crianças menores de 1 ano. Tendo em vista a este fato, na Figura 8 - Gráfico de porcentagem de resposta das puérperas entrevistadas: Nesta situação de engasgo parcial, o que você faria? Busca identificar se as entrevistadas saberiam prestar um atendimento de engasgo parcial a um bebê. Como resultado da análise dos dados, 50\% saberiam prestar este atendimento e 50\% não saberiam prestar um atendimento assertivo ao lactente vítima de um engasgo parcial. 


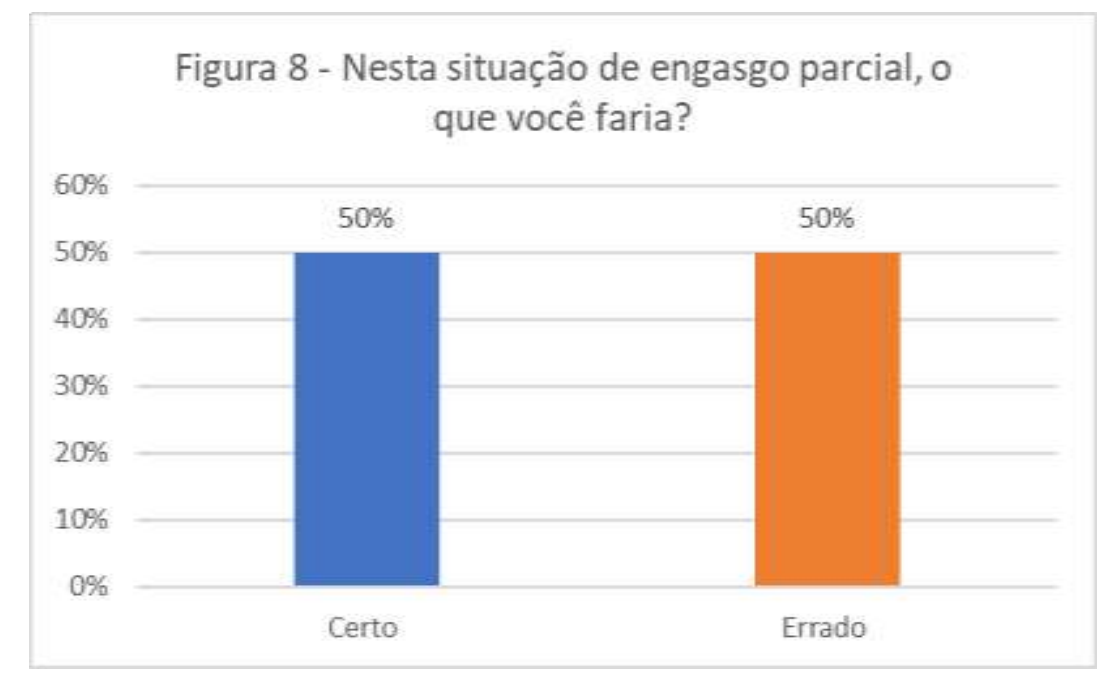

Fonte: Autores (2021).

Na Figura 9 - Gráfico de porcentagem de resposta das puérperas entrevistadas: Você sabe identificar um engasgo total? Refere-se ao engasgo total e busca identificar se as puérperas sabem identificar ou não quando o bebê possui um engasgo total. Contatou-se que $75 \%$ das puérperas sabem identificar, mas $25 \%$ não sabem.

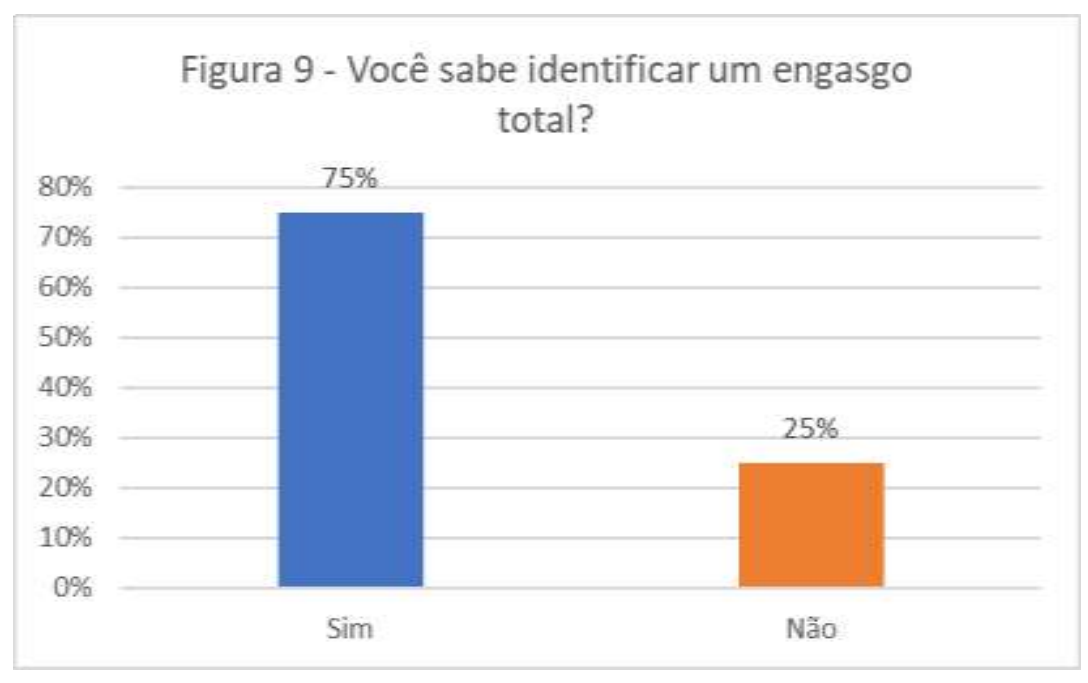

Fonte: Autores (2021).

A obstrução de vias aéreas é considerada uma emergência, e em casos graves, pode levar a vítima a inconsciência por um tempo e pode ocasionar morte por asfixia. Agir rapidamente, evita complicações (Brasil, 2017).

A seguir, na Figura 10 - Gráfico de porcentagem de resposta das puérperas entrevistadas: Nesta situação de engasgo total, o que você faria? Mostra se as puérperas sabem prestar atendimento a uma vítima com engasgo total e concluiu-se que apenas $42 \%$ saberiam prestar este atendimento e $58 \%$ não saberiam. 


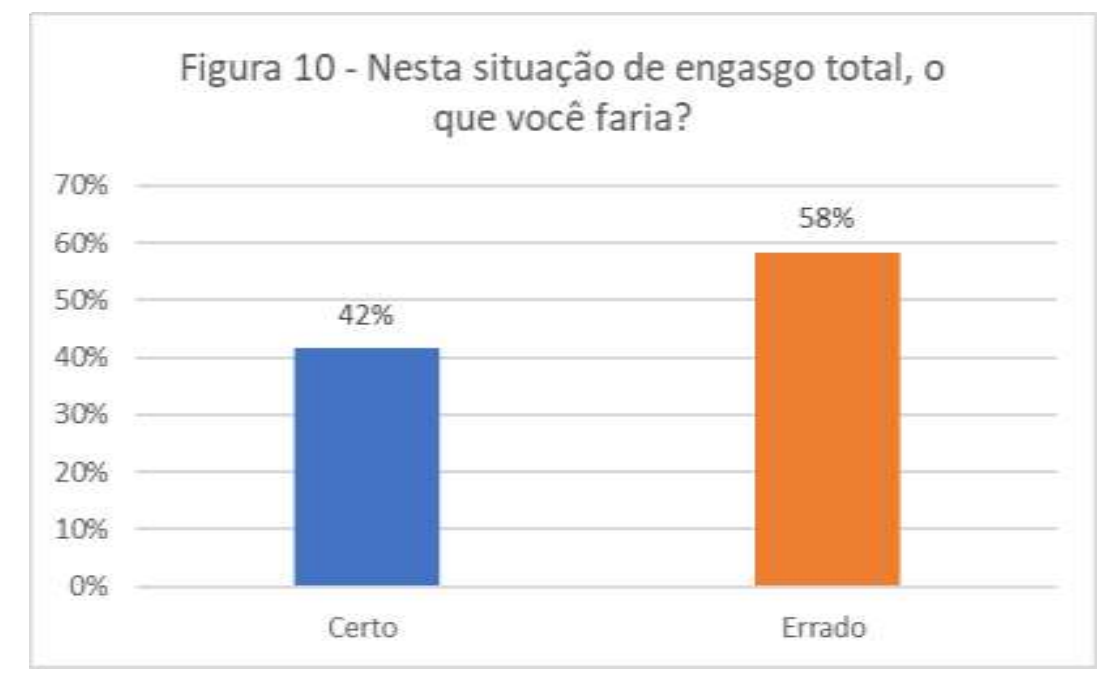

Fonte: Autores (2021).

A queda do berço, infelizmente, é um fato recorrente aos bebês. Muitas das quedas estão associadas a uma utilização inadequada dos sistemas de segurança, como por exemplo, a grade do berço, onde, por muitas das vezes, os pais não erguem por cansaço ou falta de familiaridade com o equipamento (Bordalo \& Caldeira, 2013).

Na Figura 11 - Gráfico de porcentagem de resposta das puérperas entrevistadas: Em situações de queda do berço, qual atitude você tomaria? Aborda a questão da queda do bebê do berço e 75\% das puérperas saberiam prestar este atendimento, porém $25 \%$ não saberiam prestar o socorro da forma correta.

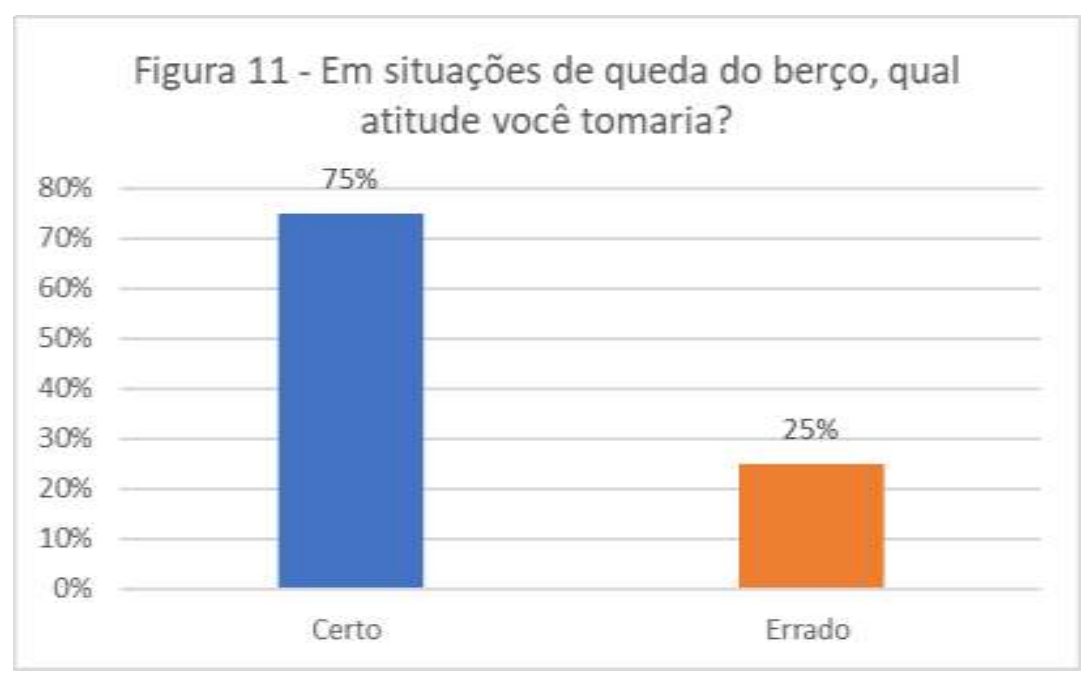

Fonte: Autores (2021).

As queimaduras podem deixar sequelas físicas, mentais e até mesmo ser fatal. As queimaduras representam acidentes que podem ser prevenidos e uma das causas que podem ocasionar morbimortalidade. A maior parte dos acidentes em crianças de até a idade escolar, é na própria residência e a cozinha é o local mais frequente para este tipo de acidente (SBP, 2020).

Em relação a queimadura por temperaturas quentes, na Figura 12 - Gráfico de porcentagem de resposta das puérperas entrevistadas: Em situações de queimadura relacionado a temperatura da água mais quente que o necessário para $o$ banho de seu filho, o que você faria? Das puérperas entrevistadas, apenas $58 \%$ saberiam agir em situações de queimadura e $42 \%$ não saberiam prestar um atendimento ao bebê com queimadura por temperatura elevada. 


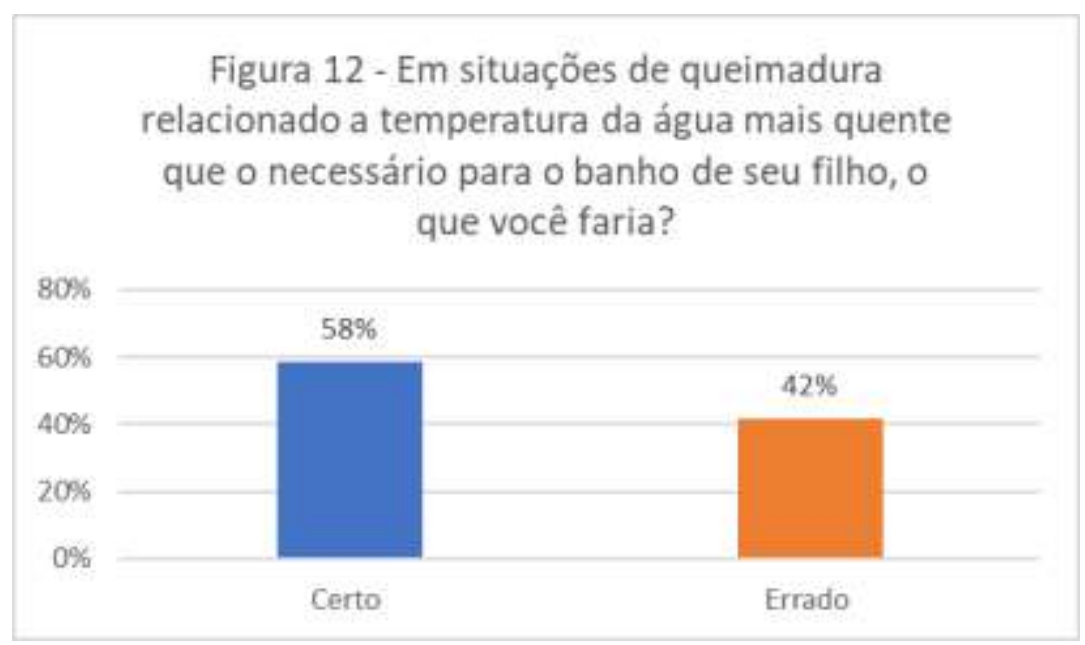

Fonte: Autores (2021).

As crises convulsivas é uma causa importante de visitas as emergências pediátricas. Informar aos familiares como proceder a vítima em uma situação de crise, é de suma importância, para que os cuidados sejam prestados de forma assertiva e deixá-los cientes da possibilidade de que existem casos de recorrência. Vale ressaltar a importância de informar aos pais, para que analisem os detalhes do episódio e, caso a crise não cesse em até cinco minutos, a criança deve ser levada para atendimento em um serviço de emergência (Brito, Vasconcelos, \& Almeida, 2017).

A última Figura 13 - Gráfico de porcentagem de resposta das puérperas entrevistadas: Em situações de crise convulsiva, o que você faria? Aborda a temática de prestar atendimento a uma vítima com crise convulsiva e contatou-se que $42 \%$ das puérperas saberiam prestar este atendimento e $58 \%$ não saberiam agir neste tipo de acidente. Vale destacar que as crises convulsivas é uma causa importante de visitas as emergências pediátricas.

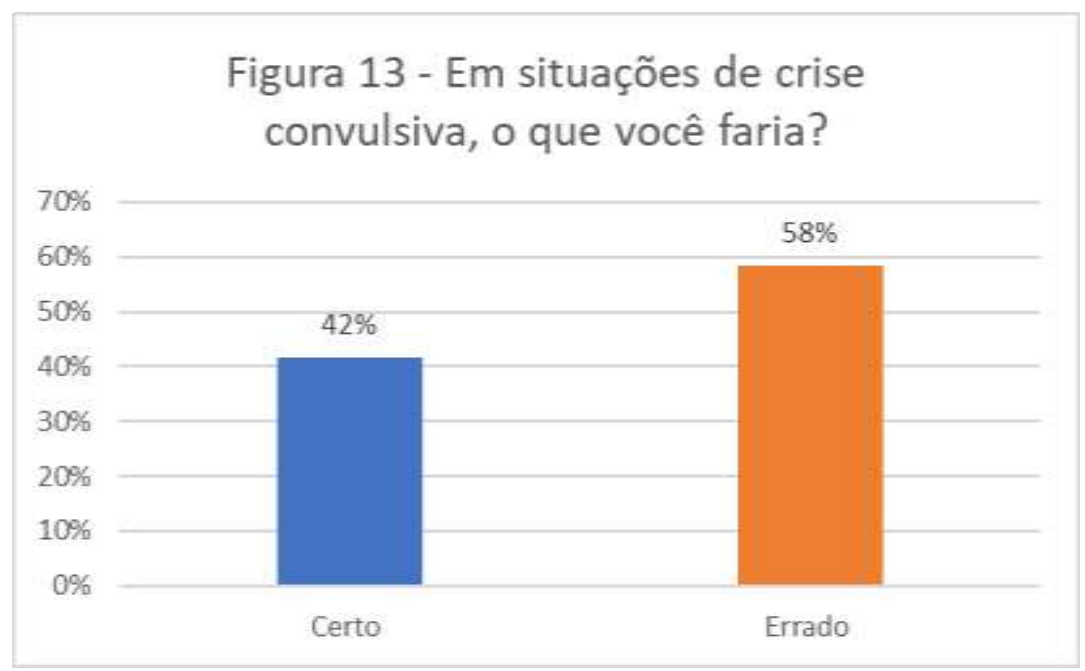

Fonte: Autores (2021).

\section{Conclusão}

Vale ressaltar que o número de sujeitos também foi diminuto devido ao atraso do parecer de autorização para coleta de dados do comitê de ética e pesquisa. Por conta desta problemática encontrada, o número amostral da pesquisa foi reduzido, além dos fatos de estarmos em uma pandemia da SARS-CoV-2, os atendimentos do ambulatório de pós-natal estão 
com o número reduzido de atendimentos e as consultas estão sendo realizadas apenas uma vez por semana e em um determinado tempo específico.

O estudo permitiu, a partir da análise dos dados, apostar as problemáticas referentes a temática do estudo.

Além desta consideração descrita anteriormente, a partir desta pesquisa, contatou-se que $83 \%$ das puérperas entrevistadas não receberam durante as consultas de pré-natal, algum ensinamento sobre primeiros socorros aos lactentes pelo profissional da saúde que a assistia. Além deste ponto destacado, vale ressaltar que 100\% das entrevistadas gostariam de receber informações dos profissionais da saúde de como prestar socorro aos bebês.

Em relação às entrevistadas que tiveram ensinamentos pelo profissional da saúde que a assistiu durante o pré-natal, o que representa $17 \%$ das puérperas, pode-se concluir que as mesmas não possuíram capacitação efetiva, pois ao responder os questionários, responderam de forma equivocada.

Vale ressaltar que $100 \%$ das entrevistadas gostariam de receber informações dos profissionais da saúde de como prestar socorro aos bebês. Logo, pode-se concluir que há uma procura, pelas puérperas, em receber este tipo de informação, porém os profissionais da saúde não compartilham estes saberem e não capacitam estas mães que tanto querem aprender a socorrer o lactente de forma efetiva.

Se as grávidas e puérperas tivessem, durante as consultas de pré-natal e pós-natal, algum ensinamento ou orientação pelo profissional da saúde sobre como agir em situações de emergência com o bebê, os problemas seriam mais fáceis de diagnosticar, pois as mães saberiam identificar o que o filho apresenta e saberiam prestar um atendimento assertivo para aumentar a sobrevida da vítima.

Por conta da deficiência dos conhecimentos das puérperas, recomenda-se trabalhos entre os enfermeiros para trazer a temática de primeiros socorros em bebês com mais frequência nas consultas com as puérperas.

Por fim, sugere-se que o enfermeiro que assiste a puérpera tenha formação em suporte básico de vida, para orientar como proceder em eventos de emergências como seus bebês, realizando assim um cuidado preventivo em situações adversas que possam ocorrer. É importante que esse profissional dê um enfoque maior em como prestar atendimento em vítimas com obstrução de vias aéreas, queimadura por temperaturas elevadas e crise convulsiva, pois a partir do estudo desta pesquisa, pode-se observar que estas foram as questões que as puérperas possuem maior dúvida.

\section{Referências}

Abder-Rahman, H. A. (2009). Engasgamento em bebês após busca às cegas com os dedos. Jornal de Pediatria, 85(3), 273-275. https://doi.org/10.1590/S0021-75572009000300015

AHA, American Heart Association. (2010). Destaques das Diretrizes da American Heart Association 2010 para RCP e ACE. http://www.heart.org/idc/groups/heart-public/@wcm/@ecc/documents/downloadable/ucm_317343.pdf

AHA, American Heart Association. (2015). Destaques da American Heart Association 2015 - Atualizações das Diretrizes de RCP e ACE. https://eccguidelines.heart.org/wp-content/uploads/2015/10/2015-AHA-Guidelines-Highlights-Portuguese.pdf

Bordalo, I., \& Caldeira, N. (2013). Implementação de um programa de Gestão de Quedas em Contexto Pediátrico Implementing a Pediatric Falls Prevention and Management Program. In $3^{\circ}$ Congresso Internacional de Qualidade em Saúde e Segurança do Doente (p. 55). https://www.researchgate.net/profile/Florentino-Serranheira/publication/236952458_Livro_de_Proceedings_-_3_Congresso_Internacional_de_Qualidade _em_Saude_e_Seguranca_do_Doente/links/0046351a7624ee771e000000/Livro-de-Proceedings-3-Congresso-Internacional-de-Qualidade-em-Saude-eSeguranca-do-Doente.pdf\#page=55

Brasil. Ministério da Saúde (MS). Biblioteca Virtual em Saúde- BVS. Engasgo. http://bvsms.saude.gov.br/dicas-em-saude/2513-engasgo

Brasil. Ministério da Saúde (MS). Banco de dados do Sistema Único de Saúde-DATASUS. http://www.datasus.gov.br

Brasil. Presidência da República. Casa Civil. Subchefia para Assuntos Jurídicos. Lei n. 7498, de 25 de junho de 1986 . Dispõe sobre a regulamentação do exercício da Enfermagem e dá outras providências. Diário Oficial da União, Brasília (DF); 1986 http://www.planalto.gov.br/ccivi 1_03/leis/17498.htm

Brito, A. R., Vasconcelos, M. M., \& Almeida, S. S. A. Convulsões. Revista de Pediatria SOPERJ, 17, 56-62, http://revistadepediatriasoperj.org.br/de talhe_artigo.asp?id=1036 
de Castro Júnior, A. R., de Paula Santos, M. A., Dourado, R. M. D., de Almeida, F. T., Santos, T. S., Brasil, B. M. B. L., \& Bezerra, C. G. (2020). Processo de trabalho em urgência e emergência intra hospitalar: impactos na saúde do Enfermeiro. Research, Society and Development, 9(8), e66985087-e66985087.

do Rosário Knechtel, M. (2014). Metodologia da pesquisa em educação: uma abordagem teórico-prática dialogada. Intersaberes.

Genesini, G., dos Santos, F., Conte, M., Lohmann, P. M., \& Zanotelli, A. (2021). Primeiros socorros na educação infantil: percepção dos educadores. Research, Society and Development, 10(1), e5210111279-e5210111279. https://doi.org/10.33448/rsd-v10i1.11276

King, I. M. (1981). A theory for nursing systems, concepts, process.

Livramento, D. D. V. P. D., Backes, M. T. S., Damiani, P. D. R., Castillo, L. D. R., Backes, D. S., \& Simão, A. M. S. (2019). Percepções de gestantes acerca do cuidado pré-natal na atenção primária à saúde. Revista Gaúcha de Enfermagem, 40. https://doi.org/10.1590/1983-1447.2019.20180211

Melo, D. E. B., e Silva, S. P. C., Matos, K. K. C., \& Martins, V. H. S. (2020). Consulta de enfermagem no pré-natal: representações sociais de gestantes. Revista de Enfermagem da UFSM, 10, 18. 10.5902/2179769237235

Moreira, T. M. M., \& Araújo, T. L. D. (2002). O modelo conceitual de sistemas abertos interatuantes e a teoria de alcance de metas de Imogene King. Revista Latino-Americana de Enfermagem, 10, 97-107. https:/www.scielo.br/j/rlae/a/QhPxFVwtvQCjHLkBgw8nvnB/?lang=pt\&format=pdf

Moura, E. R. F., \& Pagliuca, L. M. F. (2004). A Teoria de King e sua interface com o programa" Saúde da Família". Revista da Escola de Enfermagem da USP, 38, 270-279. https://doi.org/10.1590/S0080-62342004000300005

Pergola, A. M., \& Araujo, I. E. M. (2008). O leigo em situação de emergência. Revista da Escola de Enfermagem da USP, 42, 769-776. https://doi.org/10.1590/S0080-62342008000400021

Ragadali Filho, A., Pereira, N. A., Leal, I., Anjos, Q. S., \& Loose, J. T. T. (2015). A importância do treinamento de primeiros socorros no trabalho. Rev Saberes [Internet], 3(2), 114-25. https://facsaopaulo.edu.br/wp-content/uploads/sites/16/2018/05/ed3/10.pdf

SBP. Sociedade Brasileira de Pediatria. Departamento Científico de Segurança. Os acidentes são evitáveis e na maioria das vezes, o perigo está dentro de casa. Abril de 2020. https://www.sbp.com.br/fileadmin/user_upload/_22337c-ManOrient_-_Os_Acidentes_Sao_Evitaveis_1_.pdf

SBP. Sociedade Brasileira de Pediatria. Departamento Científico de Segurança. Prevenção de queimaduras em tempos de COVID-19. https://www.sbp.com.br/fileadmin/user_upload/22630b-NA_-_Prevencao_Queimaduras_tempos_Covid19.pdf

SBP. Sociedade Brasileira de Pediatria. Manual prático de atendimento em consultório e ambulatório de pediatria. 2006. https://www.sbp.com.br/fileadmin/user_upload/pdfs/ManPraticaAtend.pdf

SBQ. Sociedade Brasileira de Queimaduras. Junho Laranja. 2020. https:// www.sbqueimaduras.org.br/junho-laranja 